\title{
APLIKASI PERANGKAT AJAR KEBUDAYAAN INDONESIA BERBASIS MULTIMEDIA
}

\author{
Agustinna Yosanny; Yen Lina Prasetio; Adriani Halim; Yunair Octaarianti S.A.
}

\author{
Computer Science Department, School of Computer Science, Binus University \\ Jln. K. H. Syahdan No. 9 Palmerah Jakarta Barat 11480 \\ ayosanny@binus.edu
}

\begin{abstract}
The purpose of this research is to design a CAI application as a learning support and media to introduce the valuable cultures of Indonesia. The CAI is objected to children or people using computer. The research applied the Interactive Multimedia System Design \& Development (IMSDD) method, which consists of system requirement, design consideration, implementation, and evaluation. The result of this research is a CAI application about Indonesian culture based on multimedia that fulfills the user's need on CAI application. CAI is expected to grow users' interest about Indonesian culture, improve children's memory capability, and help create the learning process more interesting and fun.
\end{abstract}

Keyword: CAI, culture in Indonesia, Multimedia.

\begin{abstract}
ABSTRAK
Tujuan penelitian ini adalah untuk merancang suatu aplikasi perangkat ajar yang digunakan sebagai penunjang pembelajaran dan media pengenalan tentang kebudayaan Indonesia melalui media komputer. Aplikasi ini diperuntukkan bagi anak-anak pada khususnya dan masyarakat pada umumnya. Metode Interactive Multimedia System Design \& Development (IMSDD) digunakan dalam penelitian ini, yang terdiri dari system requirement, design consideration, implementation, dan evaluation. Hasil yang dicapai adalah aplikasi pembelajaran kebudayaan Indonesia yang berbasis multimedia dan terpenuhinya kebutuhan pengguna pada perangkat ajar. Perangkat ajar ini diharapkan dapat menumbuhkan rasa keingintahuan tentang kebudayaan Indonesia, meningkatkan daya ingat sejak masih kecil, dan membuat proses belajar menjadi lebih menarik dan menyenangkan.
\end{abstract}

Kata kunci: perangkat ajar, kebudayaan Indonesia, multimedia 


\section{PENDAHULUAN}

Kebudayaan merupakan keseluruhan sistem gagasan, perlakukan, dan karya yang dihasilkan oleh manusia dalam kehidupan bermasyarakat yang dijadikan milik diri dengan cara belajar (Koentjaranigrat, 2009). Kebudayaan itu mempunyai tiga wujud, antara lain: wujud kebudayaan sebagai suatu yang kompleks dari ide, gagasan, nilai, norma, peraturan, dan sebagainya; wujud kebudayaan sebagai suatu kompleks aktivitas serta tindakan berpola dari manusia dalam kehidupan bermasyarakat; dan wujud kebudayaan sebagai benda-benda hasil buatan manusia.

Indonesia memiliki 33 propinsi termasuk dua Daerah Istimewa (DI), yaitu DI Aceh dan DI Yogyakarta, dan satu Daerah Khusus Ibukota (DKI), yaitu DKI Jakarta. Masing-masing dari 33 propinsi itu memiliki kebudayaan yang berbeda. Kebudayaan daerah di Indonesia memiliki beberapa macam jenis, antara lain tarian daerah, baju adat, rumah adat, lagu daerah, masakan daerah, dan upacara daerah. Tiap-tiap kebudayaan tersebut berbeda perlakuannya pada masing-masing daerah di Indonesia.

Dengan keanekaragaman kebudayaan yang dimiliki Indonesia, sangat disayangkan apabila generasi penerus bangsa tidak mempunyai keinginan untuk ikut melestarikan kebudayaan tersebut. Kurangnya rasa ketertarikan terhadap budaya Indonesia dikarenakan minat membaca terhadap buku ilmu pengetahuan kebudayaan yang kurang, faktor lingkungan yang tidak mendukung seperti keluarga yang tidak memperkenalkan kebudayaan Indonesia atau sekolah yang tidak memiliki pelajaran tambahan atau extrakurikuler tentang kebudayaan Indonesia, menjadi faktor penyebab terpuruknya kebudayaan Indonesia.

Melihat pentingnya masalah di atas, dikembangkanlah suatu cara untuk mempelajari atau mengenalkan kebudayaan Indonesia dengan lebih menarik, yaitu dengan menggunakan multimedia interaktif. Multimedia adalah suatu gabungan atau kombinasi dari berbagai elemen-elemen yang ada seperti teks, grafik, suara, video, dan animasi. Suatu multimedia akan dikatakan interaktif bila pengguna memiliki keleluasaan dalam hal mengontrol multimedia tersebut (Vaughan, 2011). Salah satu penerapan multimedia interaktif adalah perangkat ajar atau lebih dikenal dengan Computer Assisted Instruction (CAI).

CAI merupakan suatu program instruktional yang berisi pembelajaran dengan menggunakan komputer (Kolvachickv\& Dawson, 2004). CAI terkadang dikenal juga dengan perangkat lunak pendidikan dan alat pembelajaran yang komperhensif dengan fitur manajemen dan penilaian. CAI dibuat dengan tujuan untuk memanfaatkan sumber daya yang terbatas dan menggunakan waktu dengan efisien dan efektif sehingga hasil belajar dapat meningkat. Ada beberapa tujuan dan keuntungan dari perangkat ajar yaitu self-paced learning (pengguna dapat bergerak secara lambat atau cepat bergantung pada program yang dijalankannya dan dapat mengulang kembali materi yang diinginkan), self-directed learning (pengguna dapat memutuskan apa yang ingin dipelajari), exercising of various senses (semakin banyak sense yang didapat, maka semakin banyak juga informasi yang didapat dan dapat mempermudah dalam menghafalnya) (Gates, 2001).

CAI diharapkan dapat membantu anak-anak dalam belajar sendiri dan mengurangi beban dalam mengajar. Seorang anak yang lambat dalam belajar dapat meningkatkan kemampuan dan pengetahuan mereka dengan menggunakan CAI karena CAI dapat merespon dengan cepat melalui penggunaan gambar, suara, animasi sehingga anak-anak dapat menikmati pembelajaran, dapat mengerti dan mengingat materi (Sombunsukho, et al., 2011).

Oleh karena itu, diusulkanlah suatu aplikasi CAI untuk membantu dan memotivasi anak-anak dalam belajar tentang kebudayaan Indonesia. Dengan aplikasi ini diharapkan anak-anak dapat 
berinteraksi dan menggunakan daya kreativitas mereka untuk menunjang pembelajaran menjadi lebih menarik.

\section{METODE}

Metode yang digunakan dalam penelitian ini adalah Interactive Multimedia System Design \& Development (IMSDD), yang meliputi empat tahapan. Pertama adalah system requirement, di mana pada tahap ini dilakukan pembuatan outline tentang tujuan dan sasaran sistem, mempertimbangkan target pengguna, menentukan hardware atau software yang akan digunakan, dan mempertimbangkan delivery platform yang akan digunakan. Untuk mendapatkan system requirement, dilakukan studi literatur dan pencarian data serta informasi melalui media internet. Selain itu, juga dilakukan survei kepada calon pengguna aplikasi ini, untuk mengetahui kebutuhan mereka pada aplikasi perangkat ajar kebudayaan Indonesia ini. Kedua adalah design consideration, yaitu melakukan desain metafora, tipe dan format informasi yang akan ditampilkan, struktur navigasi, dan kontrol sistem. Ketiga adalah implementation, yaitu membuat prototipe dari aplikasi dan melakukan beta test untuk mendapatkan masukan kekurangan dari aplikasi yang telah dibuat. Keempat adalah evaluation, di mana pada tahap ini dilakukan evaluasi formatif (evaluasi yang dilakukan selama proses pengembangan aplikasi) dan evaluasi sumatif (evaluasi yang dilakukan setelah proses pengembangan aplikasi selesai).

\section{HASIL DAN PEMBAHASAN}

Kebudayaan merupakan suatu peninggalan yang perlu dilestarikan, khususnya anak-anak bangsa perlu mengetahui dan mengenal kebudayaan sejak masih kecil. Banyak sekolah-sekolah yang menjadikan kebudayaan sebagai salah satu kegiatan extra kulikuler bagi anak didik mereka. Tetapi lingkungan yang kurang mendukung atau keterbatasan sumber yang dapat digunakan sebagai acuan dalam mengenal kebudayaan Indonesia. Oleh karena itu, timbullah suatu gagasan untuk membuat suatu aplikasi perangkat ajar kebudayaan Indonesia berbasis multimedia yang dapat mengakomodasi permasalahan di atas.

\section{Spesifikasi dan Install Sistem}

Aplikasi perangkat ajar ini dijalankan pada komputer. Dalam melakukan implementasi, perlu diperhatikan spesifikasi perangkat keras dan perangkat lunak baik untuk front-end maupun back-end. Untuk front-end, spesifikasi perangkat keras yang digunakan adalah Processor Intel Pentium 4 atau lebih, Memory 512MB, VGA card 128 MB, Harddisk dengan disk space 1 GB, Monitor resolusi layar $1024 x 768$ pixel, Sound Card dan Speaker, Mouse dan Keyboard, dan CD/DVD ROM. Sedangkan spesifikasi perangkat lunaknya adalah OS Windows 98 dan sederajat dan Adobe Flash Player 9.0. Untuk back-end, menggunakan perangkat keras sebagai berikut: Processor Intel Core Duo 1.66GHz, Memory 2GB, VGA card onboard 128MB, Harddisk 80GB, Monitor dengan resolusi layar 1024x768 pixel, Sound Card dan Speaker, Mouse dan Keyboard, DVD Burner, Scanner, dan Printer. Sedangkan spesifikasi perangkat lunak yang dibutuhkan adalah Adobe Flash CS3, Adobe Photoshop CS3, Smart Installer, dan VB.Net.

Perangkat Ajar diimplementasikan dalam bentuk CD (Compact Disc) yang dapat dipakai oleh semua pengguna yang memiliki komputer. Perangkat ajar ini diperuntukkan bagi semua pengguna, terutama anak-anak yang ingin belajar kebudayaan Indonesia baik di rumah maupun di sekolah. Dalam menjalankan perangkat ajar ini, pengguna terlebih dahulu harus melakukan instalasi dengan menjalankan file setup.exe. Pertama kali, akan muncul tampilan layar pembuka, pengguna hanya perlu 
menekan tombol next untuk lanjut ke layar lokasi aplikasi akan di-install. Pengguna perlu menentukan lokasi tersebut lalu tekan tombol install. Selanjutnya akan tampil layar progress peng-install-an, pengguna harus menunggu sampai aplikasi selesai di-install pada komputer lalu tekan tombol finish.

\section{Navigation Map}

Berikut merupakan Navigation Map dari aplikasi yang dibuat, baik aplikasi front-end (Gambar 1) maupun aplikasi back-end (Gambar 2).

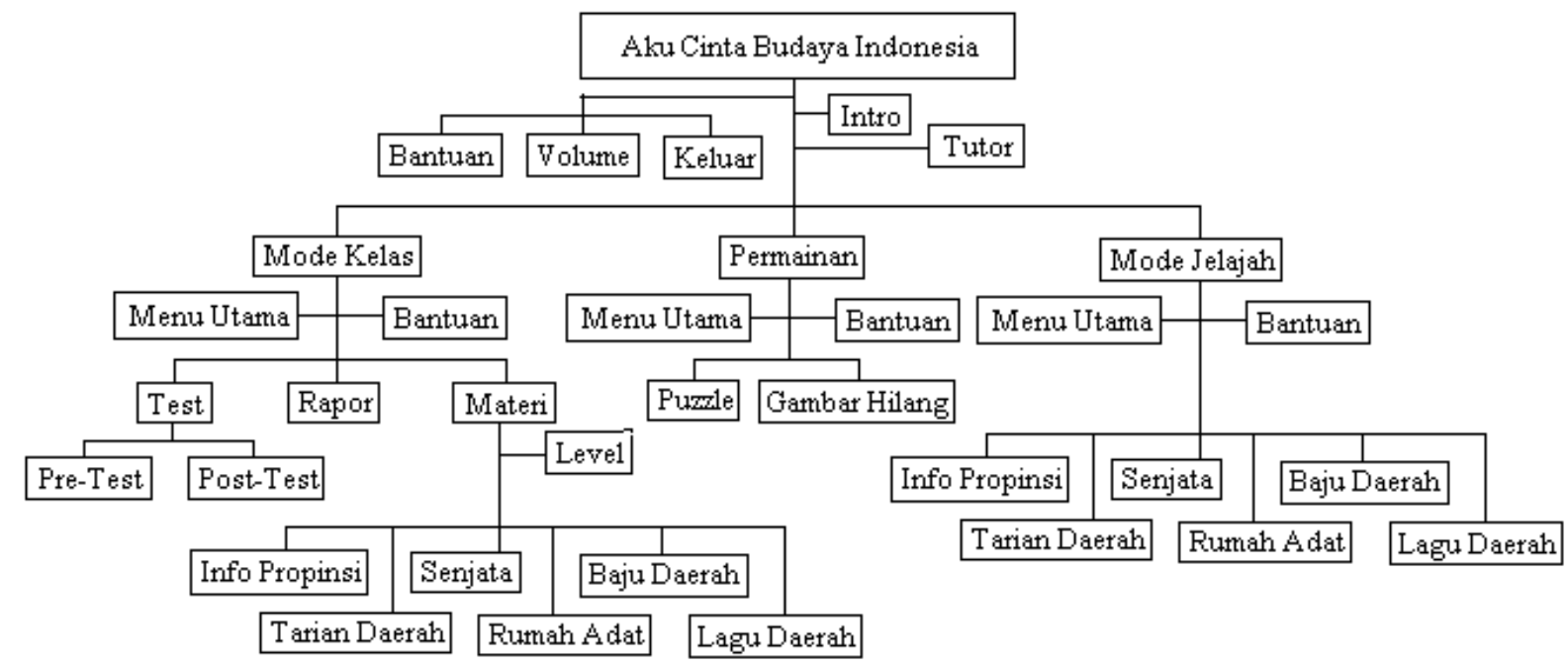

Gambar 1. Navigation map perangkat ajar kebudayaan Indonesia (front-end).

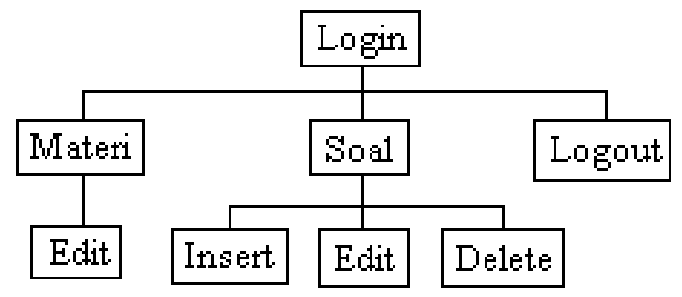

Gambar 2. Navigation map admin (back-end).

\section{Implementasi Aplikasi}

Pertama kali, jalankan file "Perangkat Ajar Kebudayaan.exe” yang merupakan hasil instalasi. Setelah itu akan tampil layar intro, di mana pengguna dapat melakukan skip pada tampilan tersebut. Setelah itu, akan ada pengenalan tutor (Gambar 3) yang berfungsi untuk memandu pengguna dalam aplikasi ini, berupa penjelasan setiap menu dan navigasi yang dapat dipilih oleh pengguna. Tombol bantuan selalu ada pada setiap layar, supaya pengguna mendapatkan bantuan setiap kali memerlukan. Tombol keluar berfungsi untuk keluar dari aplikasi. Selain itu juga terdapat tombol volume yang berfungsi untuk mengatur volume musik digunakan dalam aplikasi ini. 


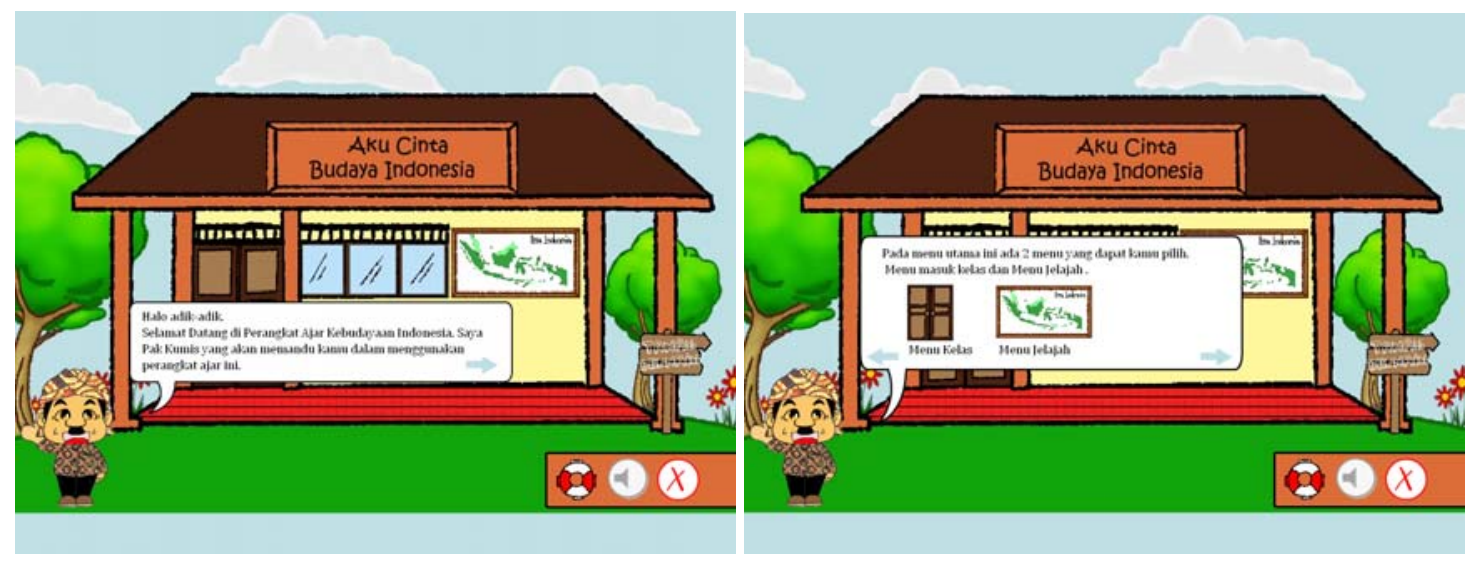

Gambar 3. Tampilan layar karakter tutor dan panduan.

Aplikasi ini mempunyai dua mode, yaitu mode kelas dan mode jelajah. Selain itu juga ada menu permainan. Apabila pengguna memilih menu kelas (Gambar 4), pengguna harus membuat profil baru atau memilih profil (jika sudah pernah menggunakan aplikasi ini sebelumnya) dan memilih karakter yang disediakan. Setelah itu akan tampil layar mode kelas, di mana terdapat menu test, rapor, dan materi.

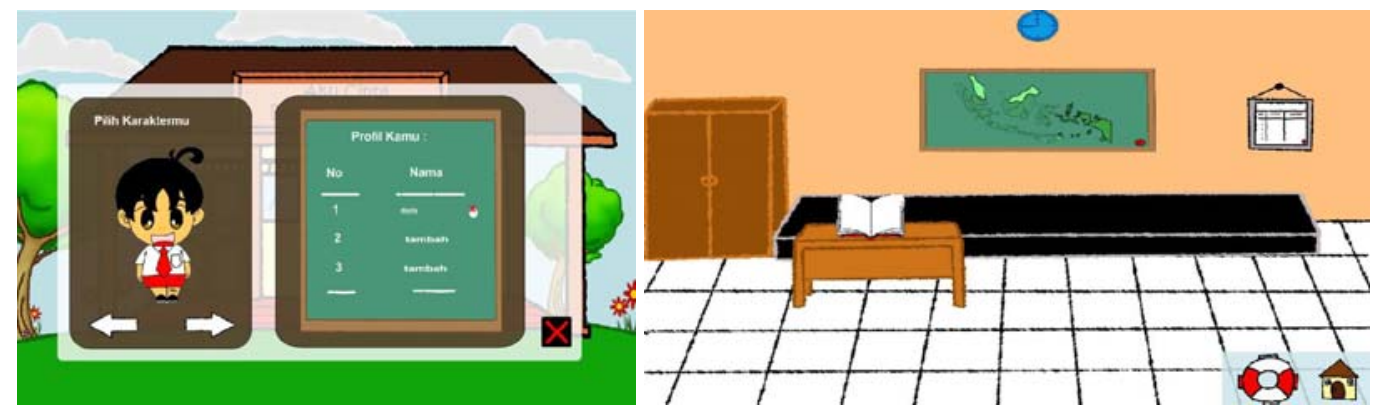

Gambar 4. Tampilan layar profile (kiri) dan mode kelas (kanan).

Mode kelas (Gambar 6) dibagi menjadi lima level pembelajaran, di mana masing-masing level mempelajari 6-7 propinsi. Pada saat pertama kali, pengguna akan dihadapkan pada pre-test untuk mengetahui pengetahuan awal dari pengguna sebelum belajar menggunakan perangkat ajar ini dan juga post-test untuk mengetahui tingkat perkembangan pengguna setelah belajar menggunakan perangkat ajar ini. Test yang disediakan dalam bentuk pertanyaan pilihan berganda. Pengguna dapat memilih salah satu pilihan yang disiapkan untuk menjawab pertanyaan yang ada. Setelah pengguna menjawab, sistem akan langsung mengecek apakah jawaban pengguna benar atau salah dan tampil seperti pada Gambar 5 Test. Pengguna juga dapat melihat nilai saat pre-test maupun post-test untuk setiap level-nya, di mana menu Rapor ini berguna untuk melihat apakah ada peningkatan kemampuan pengguna setelah menggunakan aplikasi perangkat ajar ini. 


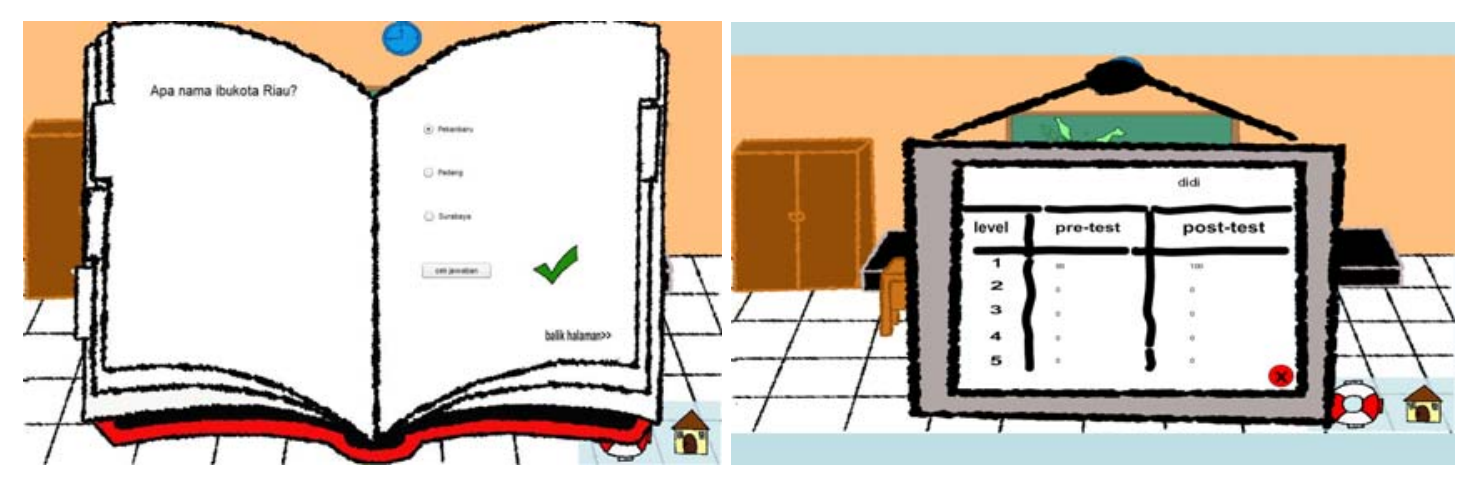

Gambar 5. Tampilan layar test (kiri) dan rapor (kanan).

Setelah itu, pengguna dapat memilih menu materi dan belajar dengan topik dibagi menjadi enam bagian, yaitu informasi propinsi, tarian daerah, senjata, rumah adat, baju daerah, dan lagu daerah.
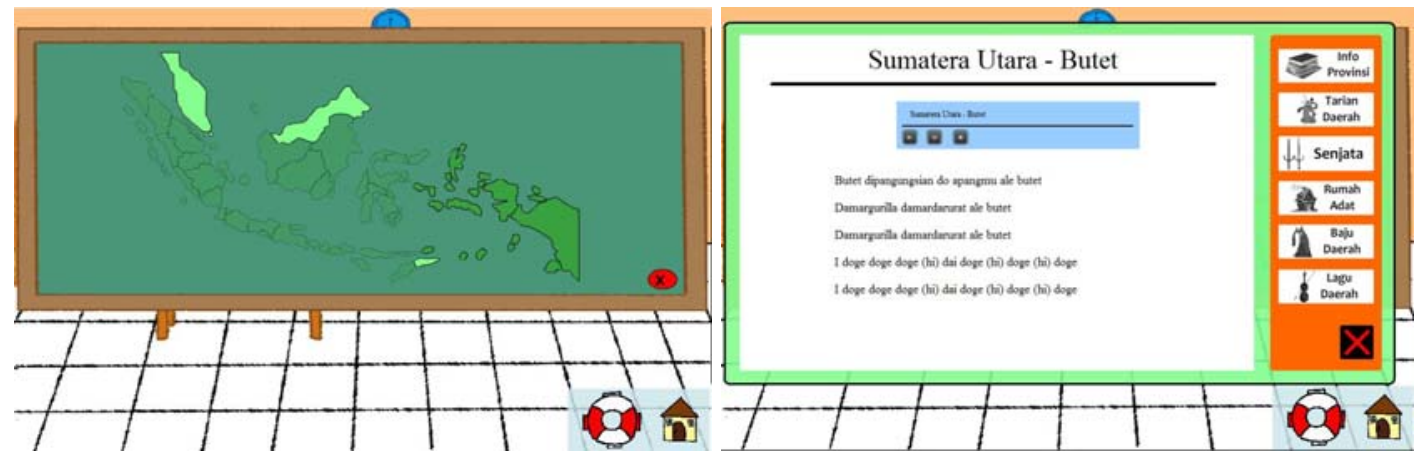

Gambar 6. Tampilan layar materi mode kelas.

Selanjutnya pengguna juga dapat masuk ke mode jelajah (Gambar 7), yang berisi sama seperti materi dari mode kelas, hanya saja pada mode jelajah tidak terdapat test, rapor, dan pembagian level pembelajaran.
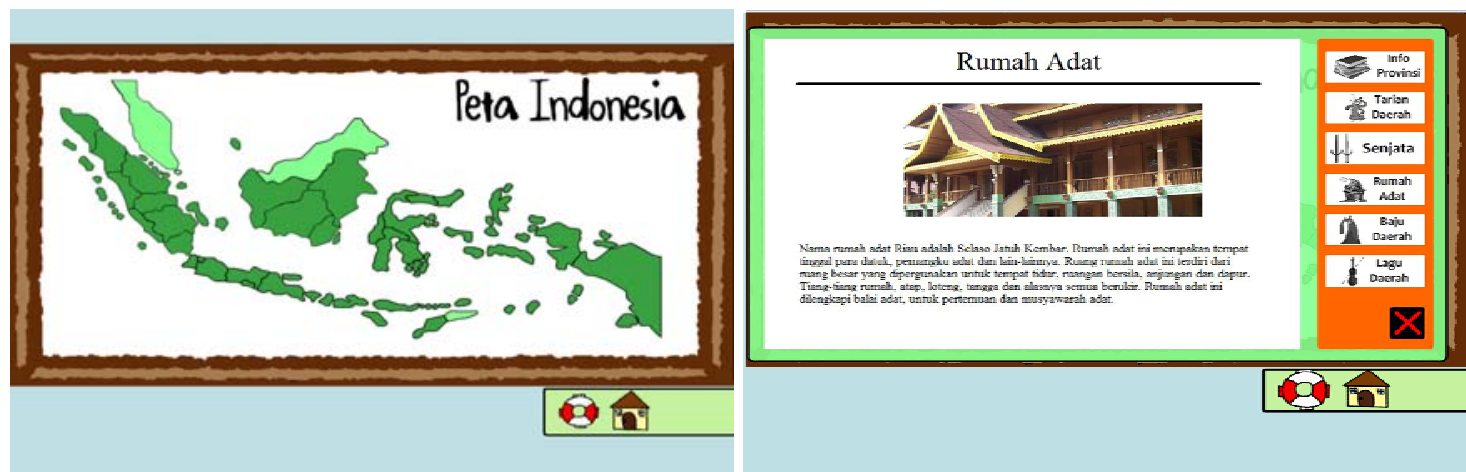

Gambar 7. Tampilan layar materi mode jelajah. 
Selain itu, pada aplikasi ini disediakan juga menu permainan agar pengguna tidak bosan belajar dengan menggunakan aplikasi ini. Hal ini dikarenakan permainan yang ada juga mendukung pembelajaran. Permainan terdiri dari 2 jenis, yaitu puzzle dan gambar hilang (Gambar 8).
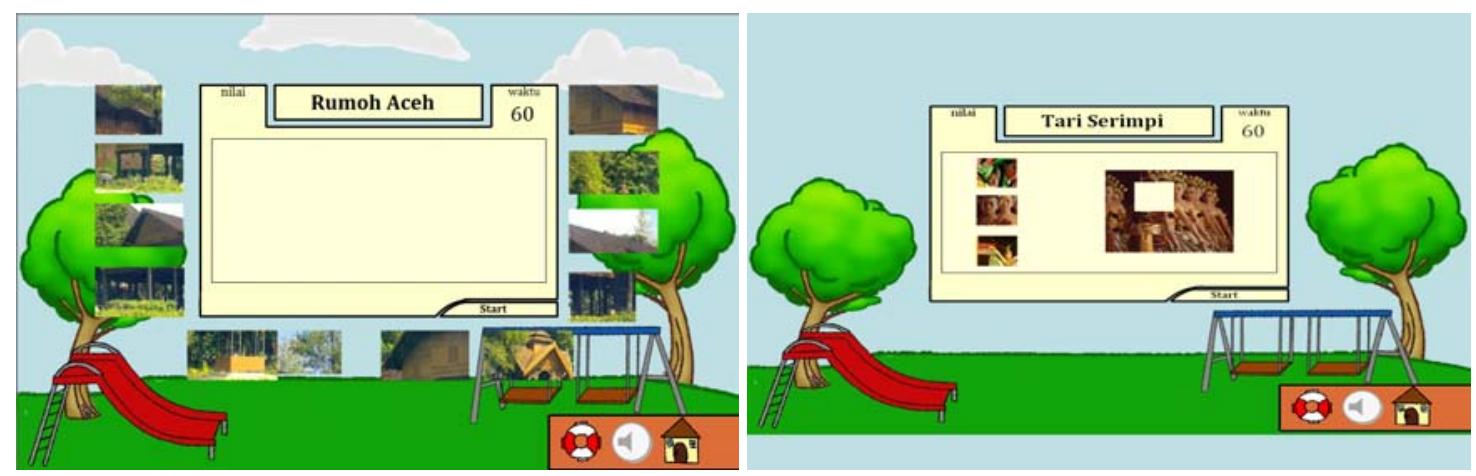

Gambar 8. Tampilan layar permainan puzzle (kiri) dan permainan gambar hilang (kanan).

Bagian admin (back-end) dimulai dengan melakukan login terlebih dahulu (Gambar 9). Setelah itu, akan tampil menu-menu yang tersedia pada aplikasi ini, seperti menu Materi, Soal, dan Logout.
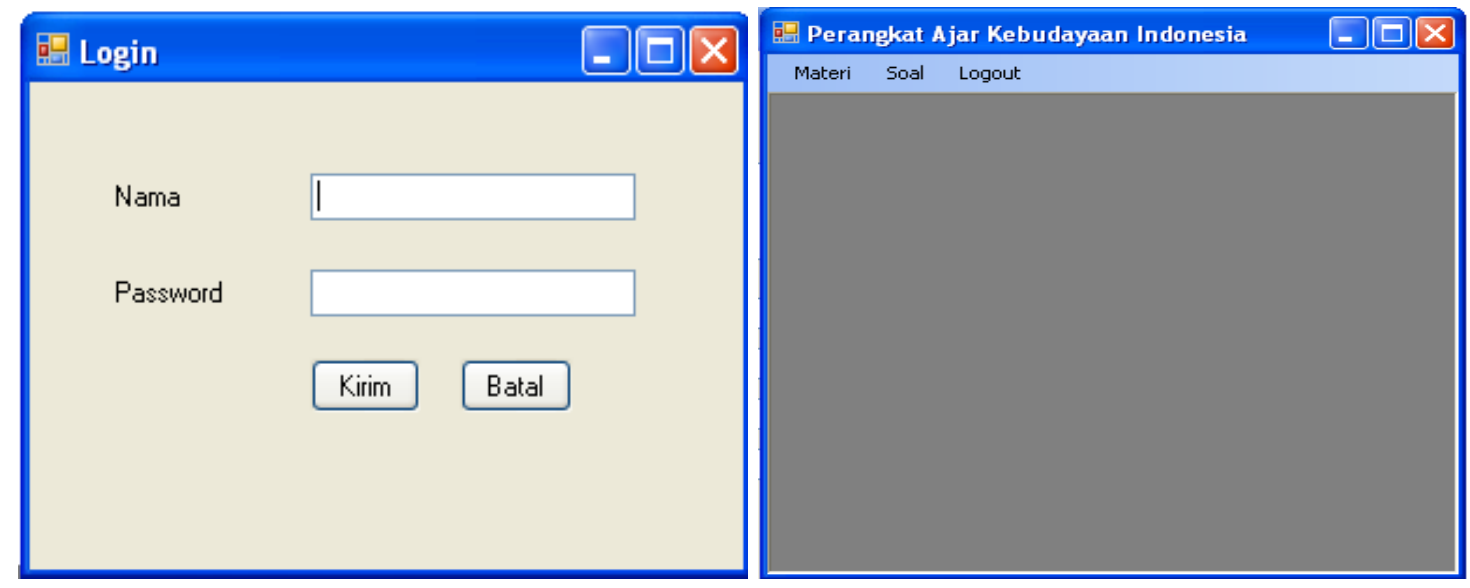

Gambar 9. Tampilan layar login (kiri) dan menu utama (kanan).

Pada menu materi terdapat submenu Edit (Gambar 10) di mana admin dapat mengganti informasi yang ada pada setiap propinsi yang tersedia (33 propinsi di Indonesia). 


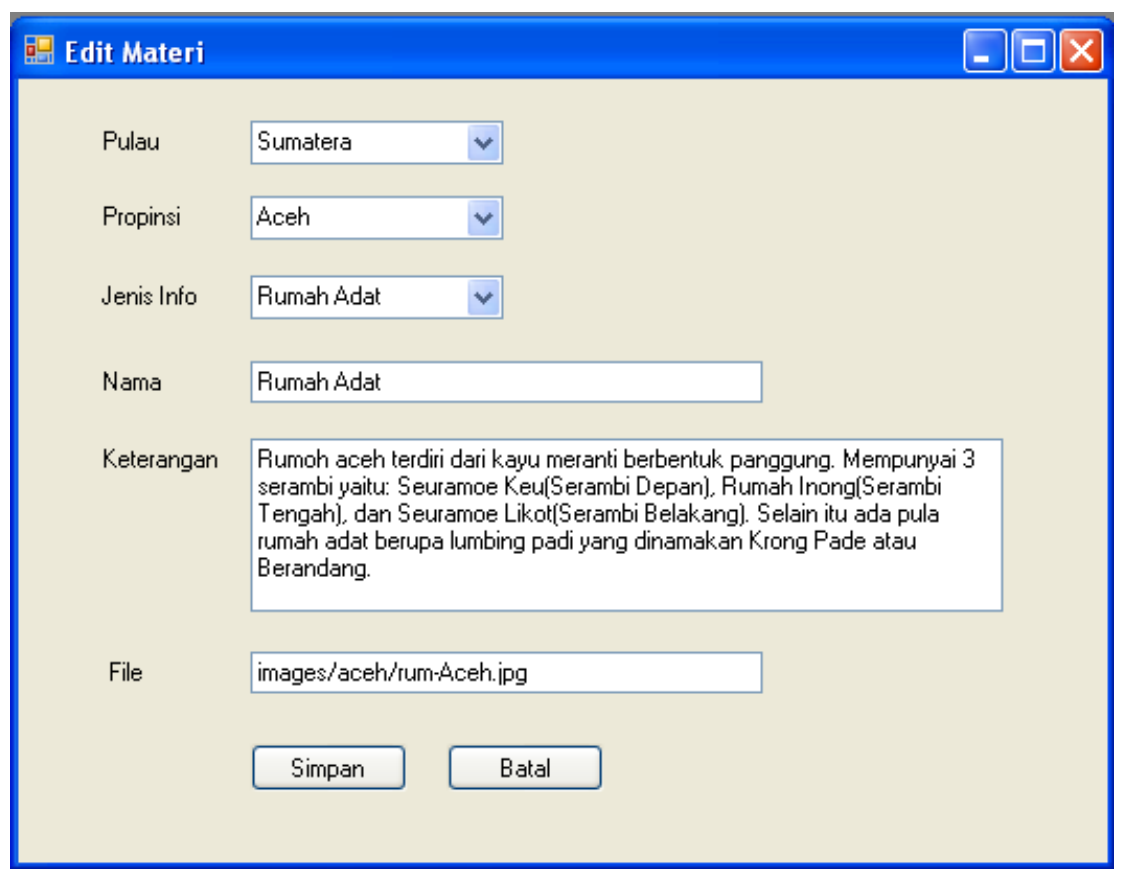

Gambar 10. Tampilan layar edit materi.

Pada menu soal terdapat submenu insert (Gambar 11), edit, dan delete di mana pada setiap submenu ini mempunyai tampilan layar yang sama, hanya berbeda tombol yang digunakan dan fungsinya.

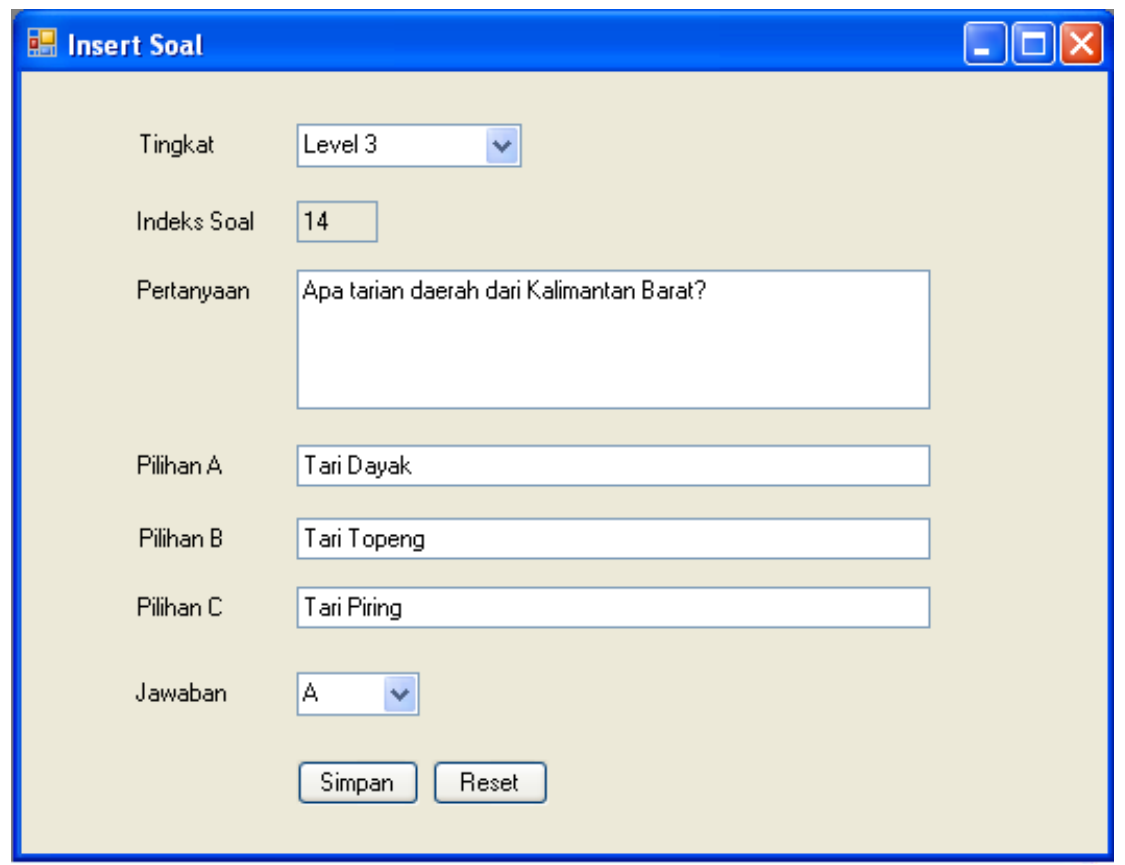

Gambar 11. Tampilan layar insert soal.

Setelah selesai menggunakan aplikasi ini, admin perlu melakukan logout dari aplikasi dengan memilih menu logout. 


\section{PENUTUP}

Berdasarkan analisis, perancangan, implementasi, dan evaluasi aplikasi perangkat ajar kebudayaan Indonesia berbasis multimedia ini, dapat ditarik beberapa kesimpulan sebagai berikut. Pertama, aplikasi perangkat ajar ini mudah digunakan, sehingga tidak menyulitkan pengguna yang belum maupun yang sudah terbiasa untuk menggunakan aplikasi ini. Kedua, aplikasi perangkat ajar ini dapat membantu pengguna dalam mempelajarai kebudayaan Indonesia dengan menyediakan materi yang lengkap dan terpadu. Ketiga, aplikasi perangkat ajar ini diperlengkapi dengan fitur permainan yang juga berhubungan dengan pembelajaran, sehingga pengguna tidak mudah bosan dalam mempelajari materi yang ada. Keempat, aplikasi perangkat ajar ini juga dilengkapi dengan sistem pretest dan post-test supaya pengguna dapat melihat peningkatan saat sebelum dan setelah belajar.

Beberapa saran yang dapat diberikan untuk pengembangan selanjutnya dari aplikasi perangkat ajar ini adalah sebagai berikut. Pertama, penambahan fitur permainan yang lebih variatif agar lebih menarik. Kedua, memperkaya soal-soal agar dapat membantu pengguna dalam mengevaluasi pemahamannya terhadap materi. Ketiga, menambahkan elemen-elemen multimedia yang lebih bervariasi, agar lebih menarik.

\section{DAFTAR PUSTAKA}

Gates, B. (2001). The Speed of Thought. Harlow: Pearson Education.

Koentjaranigrat. (2009). Pengantar Ilmu Antropologi. Jakarta: Rineka Cipta.

Kolvachick, A. \& Dawson, K. (2004). Education and Technology: an Encyclopedia. California: ABCCLIO.

Sombunsukho, Thavara, Aninbon. (2011). The development of computer assisted instruction on introduction to programming subject. AKEID'11: Proceedings of the 10th WSEAS International Conference on Artificial Intelligence, Knowledge Engineering and Databases, 55-58.

Vaughan, T. (2011). Multimedia: Making It Work. New York: McGraw-Hill. 